\title{
Factors and Drivers Effecting the Decision of Using Off-Site Manufacturing (OSM) Systems in House Building Industry
}

\author{
Hussein Elnaas ${ }^{1}$, Kassim Gidado $^{2}$, and Philip Ashton ${ }^{3}$ \\ ${ }^{1} \mathrm{PhD}$ Researcher, School of Environment and Technology, University of Brighton, Brighton, BN2 4GJ, UK, E-mail: \\ E.Elnaas@ brighton.ac.uk (corresponding author). \\ ${ }^{2}$ Principal Lecturer, School of Environment and Technology, University of Brighton, Brighton, BN2 4GJ, UK, E-mail: \\ k.i.g@brighton.ac.uk \\ ${ }^{3}$ Principal Lecturer, School of Environment and Technology, University of Brighton, Brighton, BN2 4GJ, UK, E-mail: \\ P.Ashton@brighton.ac.uk
}

\author{
Project and Production Management \\ Received May 24, 2013; revisions July 13, 2013; July 30, 2013; accept August 25, 2013 \\ Available online December 16, 2013
}

\begin{abstract}
Much has been written on Off-site Manufacturing (OSM) in construction, particularly regarding the perceived benefits and barriers to implementation. However, there seems to be a wide misunderstanding of the state of OSM associated with the concept of decision by many of those involved in decision making process within the house building industry. This has led to a demand for guidance's on decision making process for construction project leaders particularly at early project stages. Choosing a construction method for a project will require an optimum decision strategy which involves careful understanding, measurement and evaluation of a number of decision factors that can have the most influence on successful decision action. This paper, therefore, aims to identify the key decision factors to be considered at evaluation stage when choosing to use Off-Site Manufacturing (OSM) as a construction strategy in house building projects. This will reveal the key drivers for change in the industry towards the use of OSM in house building.
\end{abstract}

Keywords: Decision making, decision strategy, off-site manufacturing (OSM).

\section{Introduction}

The UK construction industry faces increasing demands to build more homes, build them quicker and build them to higher standards (Goodier et al., 2010). The industry is also expected to reduce $\mathrm{CO}_{2}$ emission and the environmental impacts of buildings, reduce overall project duration and costs, reduce defects, and eliminate accidents (NHBC House, 2009; Ross et al., 2006 and Housing Forum, 2004).

Government departments and a competitive market have driven the construction industry to review its operations and seek ways of improving its management processes and delivering of new housing (Pan et al., 2007). Traditional construction methods have struggled to meet these demands; in an effort to tackle these challenges, house builders seek alternative ways to improve their performance. It is suggested that traditional forms of construction will fail to meet future demands; Blismas and Wakefild (2007) state that OSM can contribute to addressing some of the challenges facing the construction industry. Whilst, Goodier et al., (2010) stated that offsite production systems have been promoted as a part of the solution to addressing these challenges. Further, Ogden, (2010) emphasised that the adoption of new practices and technologies is seen as one of the key survival strategies of improving construction in the 21 st century.

Gidado (2013) suggests that there is tremendous benefit in either applying production management expertise on construction sites or transferring construction activities to the production yards or plants for effective management. The potential of using offsite production to reduce cost, time, defects, health and safety risks and environmental impact and a consequent increase in predictability, whole life performance and profits on long term has been well established (Venables et al., 2004; Gibb and Pendlebury, 2005). It is further seen as a key vehicle for driving process and efficiency improvements within the house building sector (Housing Corporation, 2007). Despite this potential, Goulding et al., (2012) stated that the uptake of OSM is much lower than expected in the UK construction industry. Pan et al. (2007) have expressed a similar view that the use of OSM in the UK housing sector was very low, with most top 100 house builders rarely using OSM.

Using OSM has the potential for further use in the UK house building industry, however, literature has identified that there are many issues and questions that need to be addressed regarding the decision making process. This research agrees that the identified challenges can be met 
through the implementation of offsite technologies to house building, but this potential can only be met if the decision to use OSM is better understood and properly guided. Therefore the following objectives were set in order to establish a decision selection criteria: 1) Identify key drivers for change to adopt OSM in the housing sector, 2) Review the characteristics associated with the current decision making procedure used to select OSM, 3) Identify the key factors used at the evaluation stage of decision making to selecting or considering to use OSM, 4) Establish a selection criteria to use OSM as construction strategy for housing.

\section{Research Methodology}

The scoping study employed mixed methods throughout this research using both qualitative and quantitative approaches for data collection that involved semistructured interviews and case studies.

The literature review established the need of using OSM as a strategy for house building projects and a robust understanding of the concept of decision making with regard to using OSM. Interview questions were developed from issues highlighted by the literature review, in particular the need to improve decision making when it comes to OSM choice. The primary objective of the data gathering was to canvass construction practitioners' opinions and views based on their experience of decision making to use OSM systems in the construction houses.

A total of 30 interviews were carried out using semistructured form with leading construction professionals of the housing industry particularly members of BuildoffSite (BoS) organisations. All the interviewees were senior managers and directors with responsibility for making company policy decisions. They include clients, contractors, consultants, project managers, design managers and contract/construction managers. This mix of firms and roles has allowed a range of views and opinions to be gathered in order to establish a robust data set to explore how decisions to use OSM systems were currently being made by professionals in the house building industry.

Following the literature review and interviews, the research analysed and cross checked those factors that were emerging against known outcomes via case studies. A further 15 case studies of projects using OSM systems were conducted, which provided a comprehensive set of factors and criteria used when considering to use OSM systems for house building projects. The case study approach focused on the identification of key factors and the impact of each factor on the outcome of the decision made. Each case study shared facts that had been considered during the decision making process to use OSM systems instead of onsite construction methods.

The case study approach focused on the identification of the impact of each factor on the outcome of the decision made. The outcomes were used to establish the selection criteria that can assist in the decision making to use OSM system as a strategy for construction of houses.

\section{The Concept of Decision Making to OSM}

Decision making is an on-going task, carried out through the construction project's life cycle. It is a process solving activity, through making a conscious choice or selecting to achieve an objective or willing outcome of a project. Decision making process is concerned with the finding and selection of satisfactory and optimal alternatives that is the best possible solution for particular decision matter (Choo, 2006).

According to Lucey, (1997), all decisions must decide by some means to choose the outcome or outcomes which are desirable to decision maker(s) and to do so after some form of appraisal of the situation. Further, Choo (2006) stated that an alternative is considered optimal if it is greater to all other alternatives when a single, consistent set of criteria is used to compare all the available alternatives. Thus, if one is to choose a construction strategy, making a decision should be based on a number of pre-established key factors and drivers in order to choose the optimum construction strategy for a project.

This research has focussed on the decision making of choosing between two decision outcomes: 'offsite construction' versus 'onsite construction' strategy for house building projects. Industry professionals have expressed their interest in the process of Off-Site Manufacturing (OSM) systems in construction, however, due to the lake of understanding of the decision making process, some professionals have avoided using these technologies entirely (Ogden, 2010). A major reason, established by Pasquire and Gibb (2002), is that clients and practitioners are unwilling to adopt OSM because they have difficulty ascertaining the benefits that would add to their project.

Whilst there exists decision support systems and evaluation techniques, Pasquire and Gibb (2002) argued that decisions to use offsite techniques in construction are still largely based on unreliable and subjective approaches. Further, Blismas et al. (2006) also stated that the decision making process used to evaluate what extent a component or building system should be produced offsite is inadequate within the industry.

According to CIRIA (2000), the decision making process used to evaluate the application of OSM in the construction process is poorly understood. Pasquire et al (2004) stated that the decision making process is inadequate within the industry, while Blismas et al (2006) pointed out that decisions regarding the use of OSM are unclear and complex. Pasquire and Gibb (2002) confirm that the decision seems to be based on anecdotal evidence rather than rigorous data, as no formal measurement procedures or strategies are available. Pan et al (2008) argues that with increasing pressure on construction professionals to improve efficiency and to make decisions quickly, there is a lack of rational, robust and balanced decision criteria for building system selection in house building. There has been very little evidence to suggest that the existing decision making systems and tools designed in the context of OSM meet the current needs of the construction practitioners. This therefore confirms the need to develop a decision selection criteria framework or mechanism that is based on thorough knowledge and understanding of decision making methodology and its potential application to guide the selection to use OSM systems in house building projects.

\section{Results of the Study}

The key results in line with the research objectives identified are presented in the following sub-sections:

\subsection{Drivers to Adopt OSM in the Housing Industry}


The existing literature reveals a wide range of driving forces for utilising offsite technologies in different sectors of the construction industry. Some research projects such as Construction Excellence (2006) have revealed the drivers within the project context, which identified five drivers for change to using offsite technologies that have been recognised in the UK's house building industry: costumer focus, quality driven agenda, committed leadership, integration of processes and teams around the product and commitment to people. Further, Jaillon and Poon (2009) expressed that one of the most potential drivers of using OSM is to address the environmental challenges in terms of energy efficiency and waste reduction. Nehmens and Mullens (2009) suggest that improving financial efficiency through economics of scale through mass customisation may be the key driver. Burgen and Surgen (2006) argue that improving the social aspects of people's lives by providing job opportunity in factory environment (which is safer), training and better working conditions is the key driver for change.

Further, Pan et al., (2005) argued that the most significant drivers for adopting offsite technologies are addressing skills shortages, delivering within agreed time and costs and achieving high quality. A study by Rose, et al. (2006) also identified five drivers for change in the context of house building, these are: shortage in housing supply, skills shortage, concerns about quality, changes to Building Regulations and environmental performance. Whilst the literature review provided existing drivers to the general implementation of OSM in the construction industry, this research has reviewed the drivers for adopting OSM with specific reference to decision making. The findings have been established from the 30 interviews with practitioners in the UK housing industry based on their on-going projects or past experience. 12 key drivers for change in the house building industry have been identified. These drivers were then categorised into 5 main categories: technical, economic, environmental, organisational and social.

As shown in Table 1, using simple averages of the responses from the interviewees, the 5 categories were ranked in order of importance. The results show technical, economic, environmental, organizational and social scoring $82 \%, 73 \%, 67 \%, 61 \%$ and $51 \%$, respectively. Technical is the top category, which includes shortage in housing supply, projected skills shortage and concerning quality of new build homes. House builders believe that the use of OSM systems can improve the rate of delivery of houses to meet demand/target and quality of new housing. They also indicated that industry's skill shortage can be addressed by using OSM system because most of the work takes place in the factory environment. Although, OSM in itself may not reduce the amount of labour; instead it changes the location of work and the workforce from site to factory, which enables the use of the available labour more effectively and efficiently in a more controllable environment.

With all five categories recording a weighting above $50 \%$, it may be argued that all categories will have a significant influence in bringing change to the house building industry. One possible reason for this may be that practitioners and clients have recognised the benefits of implementing the system in the construction of houses and therefore expressed the need to fully drive the required change enthusiastically.

\subsection{Constraints to OSM Implementation}

Pan et al (2004) suggests that there is little understanding within the UK construction industry of the process of manufacturing components offsite which exacerbate the effect of constraints impacting against using OSM. In such circumstance, Armstrong at al., (1999) established that decision makers face a range of possible constraints that may include a lack of alternatives, no clear criteria, time and cost constraints; imperfections of the decision makers' perceptions; or incompatibility between attitudes.

Furthermore, Pan et al., (2008) stated that other factors that further increase the effect of the constraints include increasing alternatives to choose from, more uncertainties about future requirements and the need to make quick decision. While Blismas and Wakefield (2007) argued that the most significant constraint to the use of OSM in the construction is its associated costs.

Table 1. Key drivers for using OSM in house building

\begin{tabular}{|c|c|c|c|}
\hline Categories & Drivers & \multicolumn{2}{|c|}{ Percentages $(\%)$} \\
\hline \multirow{3}{*}{ Technical } & Shortage in housing supply & 87 & \multirow{3}{*}{82} \\
\hline & Projected skills shortage & 76 & \\
\hline & Concerning quality of new housing & 83 & \\
\hline \multirow{2}{*}{ Economic } & Reduction in overall project cost & 69 & \multirow{2}{*}{73} \\
\hline & Integration of project processes & 76 & \\
\hline \multirow{2}{*}{ Environmental } & Environmental performance of buildings & 46 & \multirow{2}{*}{67} \\
\hline & Reducing environmental impacts during construction & 86 & \\
\hline \multirow{2}{*}{ Organizational } & Revisions to Building Regulations to support OSM & 64 & \multirow{2}{*}{61} \\
\hline & Government and Industry's agenda and concerns & 58 & \\
\hline \multirow{3}{*}{ Social } & Employment opportunities away from building sites & 48 & \multirow{3}{*}{51} \\
\hline & Reduction in accidents and ill health & 46 & \\
\hline & Product and end-user focus & 58 & \\
\hline
\end{tabular}


Table 2. Key constraints to use OSM in house building

\begin{tabular}{|c|c|c|c|}
\hline Categories & Constraints & Perc & \\
\hline \multirow{4}{*}{ System } & Culture resistance - poor public perception of OSM & 39 & \multirow{4}{*}{61} \\
\hline & Lack of understanding of OSM by local authorities & 48 & \\
\hline & Low market demand on OSM homes & 81 & \\
\hline & Mortgage to OSM due lack of awareness of the system & 77 & \\
\hline \multirow{3}{*}{ Process } & Early design freeze & 92 & \multirow{3}{*}{70} \\
\hline & Complex interfacing between systems and tolerance issues & 71 & \\
\hline & $\begin{array}{l}\text { Possible increased consequences of incidents onsite due to large } \\
\text { units and heavy loads }\end{array}$ & 48 & \\
\hline \multirow{3}{*}{ Regulatory } & Regulations are too old to cover all offsite aspects & 73 & \multirow{3}{*}{59} \\
\hline & Lack of existing codes and standards to OSM & 62 & \\
\hline & No legal framework available to support OSM & 42 & \\
\hline \multirow{3}{*}{ Logistics } & Site and access constraints & 63 & \multirow{3}{*}{48} \\
\hline & Crane requirements and associated costs & 24 & \\
\hline & $\begin{array}{l}\text { Difficult long-distance transport from/to manufacturing plants, with } \\
\text { associated issues }\end{array}$ & 57 & \\
\hline \multirow{3}{*}{ Resources } & Skills shortages & 87 & \multirow{3}{*}{64} \\
\hline & Limited UK capacity in OSM to enhance its use and efficiency & 66 & \\
\hline & Limited expertise in the marketplace of the system & 39 & \\
\hline \multirow{4}{*}{ Cost Implication } & Expensive available skills & 23 & \multirow{4}{*}{54} \\
\hline & Higher capital cost & 71 & \\
\hline & Expensive with comparison to traditional methods & 64 & \\
\hline & Design fees seen more costly & 58 & \\
\hline
\end{tabular}

Although this research has provided a body of evidence to suggest that if the key drivers are understood and applied, it could enhance the use of OSM in house building industry, it also identified 20 most significant constraints to the use of OSM. These constraints have been categorised into 6 main categories and tabulated as shown in Table 2.

Interestingly, the constraints to using OSM identified from practice are very similar to those identified from the existing literature. Similarly, they are also reflective of the industry's traditional fragmented approach to construction.

\subsection{Decision Factors Influencing the Adoption of OSM in House Building}

Having identified the drivers and constraints, the research further used interviews and case studies to identify a robust set of decision factors that need to be considered. These factors have been measured and ranked in order of significance, depending upon the project specific requirements.

The research produced a list of 122 decision factors that have an influence on decision making process when considering OSM. These factors were then categorised into 16 themes of decision factors for ease of handling and comprehension.

The data obtained from both interviews and case studies were analysed using a five point likert scale. In order to establish a ranking for each of the 16 categories (themes), the frequency index and importance index have been established. The results are shown in Table 3. The frequency index $(\mathrm{Fi})$ was established using the following function:

$$
\text { - } \mathrm{Fi}=100 * \sum(\mathrm{f} / \mathrm{F})
$$

Whilst, the importance index (Ip) was established using the following function:

$$
\text { - Ip }=100 \sum(\mathrm{a} * \mathrm{f}) / \mathrm{AF}
$$

Where:

$$
\begin{aligned}
& a=\text { the weighting } \\
& A=\text { maximum possible weighing } \\
& \mathrm{f}=\text { frequency of possible weighting } \\
& \mathrm{F}=\text { total number of respondents }
\end{aligned}
$$

The research has confirmed that the decision factors associated with time, quality and cost have highest impact on the decision for using OSM in the house building industry. They score an importance index of $97 \%, 76 \%$ and $60 \%$ respectively. The rating for time is far and above all other factors. There is an overall saving in programme time; this reduction is obtained through the overlapping of offsite and onsite activities which would normally be done in a serial sequence using traditional methods. Thus, the reduction in project time should lead to reduction in the overall cost of project. However, due to the reduced on- 
site time, there should also be a reduction in the preliminary costs associated with the major contractor's site setup costs.

Achieving the highest quality was also highlighted as one of the main key factors, may be because quality control and assurance procedures are easier to apply in the factory environment. Working under factory conditions also gives better control, productivity and quality of end product; where offsite works are completed in advance of the onsite installation, the products can be tested before they are transported and incorporated into the building.

The predictability, productivity, interface issues, environmental issues, performance, labour, safety and lack of space, are considered as moderately important. Predictability of building performance factor was on the top of moderately important factors with a $42 \%$ score, may be because clients' need to be able to control their risks and uncertainty by reducing or eliminating unknowns. The productivity factor is next on the list with an importance standing at $35 \%$. Safety, project complexity and logistics issues factors were identified as neutral/usually importance influence. The less affected factors in terms of the importance were availability of resources, planning and market condition.

From the data review and analysis of the robust set of factors, the research has established the 10 most important factors that can have potential influence on decision when considering OSM as a construction strategy, namely highly important and moderately important as shown in Table 3.

\section{Discussion on the Challenge to using OSM in House Building}

Since Egan Report (1998), which identified the use of offsite innovations in construction as a part of the solution for improving its management process, various industry and research initiatives have attempted to consider the concept in the construction industry. A study by Mullens and Arif (2006) demonstrated that significant cost savings and efficiency are achievable with manufactured construction. However, to quote Crowley (1998), 'solutions from the manufacturing industry cannot be simply applied to problems of the construction industry, without those solutions being re-engineered themselves'. Further, Polat et al. (2006) demonstrated that simply moving efforts offsite does not necessarily guarantee efficient construction.

Several researchers have identified many issues in manufacturing that could be beneficial at strategic-level (Gann, 1996; Crowley, 1998; Gibb, 2001), but many others have documented neither benefit at operationallevel (Pan and Arif, 2011) nor at tactical-level.

It is therefore essential that the decision for using OSM is viewed from a project-wide perspective of key project drivers, and a suitable strategy is developed to optimise its use during the evaluation stage, which can be different from project to project. This research, therefore, has looked into the drivers in terms of decision making context in housing sector. With regard to decision making process, the research considered the Three-Levels of management in the following perspective:

- The drivers and constraints represent the Strategiclevel.

- The robust set of decision factors represents the Tactical-level.

- At the Operational-level, there should be a mechanism or system that can aid construction practitioners to evaluate and quantify the decision system establishing significance for predictable outcomes of a project

Table 3. Key themes of decision factors to OSM

\begin{tabular}{|c|c|c|c|c|c|}
\hline \multicolumn{2}{|r|}{ Themes } & \multicolumn{2}{|c|}{ Responses \% } & \multicolumn{2}{|c|}{ Importance Impact } \\
\hline $\mathrm{F} 1$ & Time & 45 & 100 & 97 & \multirow{3}{*}{ Highly Important } \\
\hline $\mathrm{F} 2$ & Quality & 39 & 87 & 76 & \\
\hline $\mathrm{F} 3$ & Cost & 36 & 80 & 60 & \\
\hline $\mathrm{F} 4$ & Predictability & 26 & 58 & 42 & \multirow{7}{*}{$\begin{array}{l}\text { Moderate } \\
\text { Important }\end{array}$} \\
\hline F5 & Productivity & 22 & 49 & 35 & \\
\hline F6 & Interface issues & 21 & 47 & 29 & \\
\hline F7 & Environment issues & 20 & 44 & 26 & \\
\hline F8 & Performance & 19 & 42 & 26 & \\
\hline F9 & Labour & 16 & 36 & 23 & \\
\hline F10 & Lack of space & 15 & 33 & 21 & \\
\hline F11 & Safety & 13 & 29 & 14 & \multirow{3}{*}{ Usually Important } \\
\hline F12 & Project Complexity & 10 & 22 & 12 & \\
\hline F13 & Logistics Issues & 10 & 22 & 10 & \\
\hline F14 & Availability of Resources & 8 & 18 & 8 & \multirow{3}{*}{ Not Important } \\
\hline F15 & Planning Issues & 6 & 13 & 5 & \\
\hline F16 & Market Condition & 5 & 11 & 4 & \\
\hline
\end{tabular}




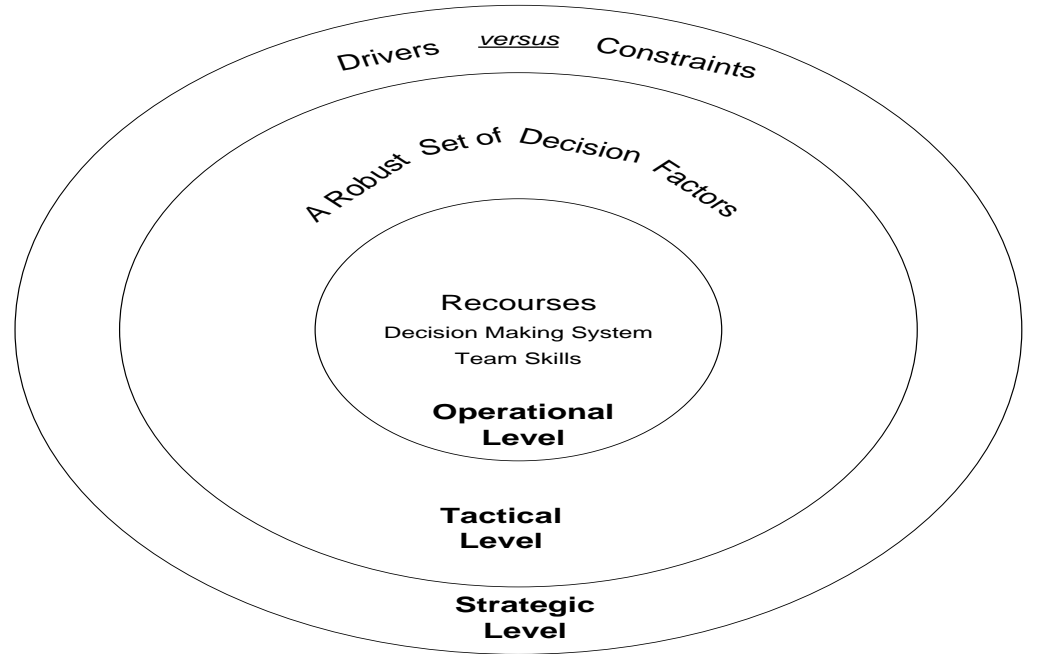

Fig. 1. Illustrates drivers, constraints and decision factors to OSM on the Three-Levels of management process

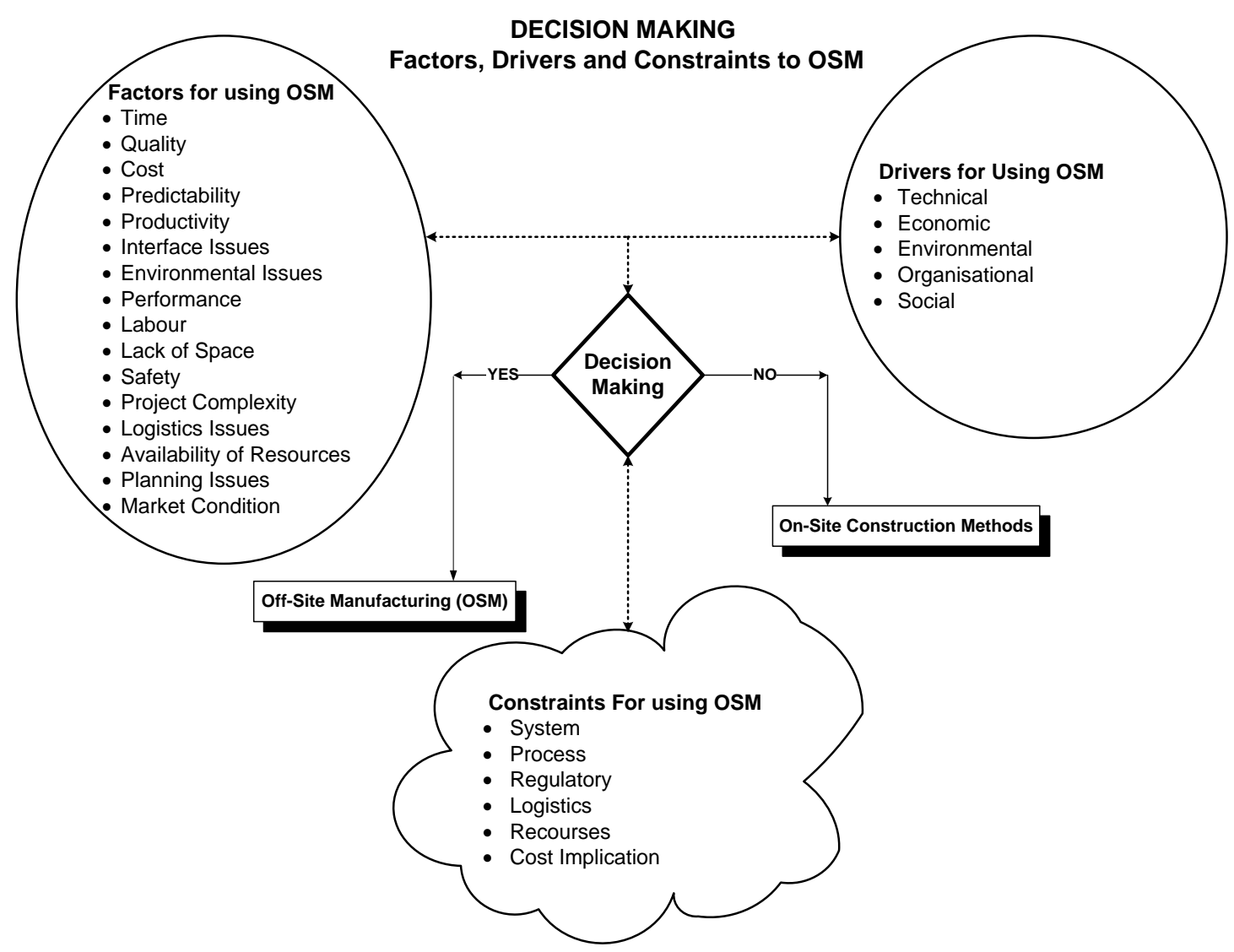

Fig. 2. Relationships between drivers, constraints and decision factors to OSM

This is depicted as shown in Fig. 1.

The global aim of this research project is to develop such mechanism or system that can be used at the operational-level. This will enable decision makers to evaluate the project characteristics before choosing to use OSM systems as a construction strategy.

Fig. 2 graphically maps out the relationship between the drivers, constraints and decision factors in the context of decision making process when considering OSM as strategy for house building construction.
Figs. 1 and 2 highlight that the decision for using OSM systems in house building is driven by defining the project priorities in form of key factors that can have influence on decision making based upon their significance, and then considering the benefits of various options (offsite vs. onsite) against those drives. The model clearly indicates the significance of feedback and continuous improvement of the quality of the decision making process.

The identified five key drivers and the six constraints categories are used as framework to guide the project decision making process, each with sub-divisions as were presented in previous sections. Whilst the project drivers 
are usually seen to be the important issues in decision making process, it is the constraints that have the greater potential to influence the project outcomes. These together will be used to identify the potential impacts on decision outcomes on whether to use or not to use OSM as construction strategy for a project.

The research confirms that time-quality-cost management triangle are the main key factors having importance standing at $97 \%, 76 \%$ and $60 \%$ respectively. Time is the most effective factor on decision to use OSM. There is an overall saving in programme time; this reduction is obtained through the overlapping of offsite and onsite activities. It is expected that the reduction in project time should lead to reduction in the overall cost of project including reduction in the preliminary costs associated with the major contractor's site setup costs.

Cost is still challenging factor to OSM; using OSM may appear more expensive than onsite methods due to lack of understanding of the construction process. However, if considering long term benefits of using the system then this perception will dramatically change. Achieving the highest quality was highlighted as an important factor because quality control and assurance procedures are easier to apply in the factory environment. Working under factory conditions will give better product control, productivity and quality of end product. Therefore, OSM can be a strategy which if properly implemented could deliver the specified quality within the cost plan and the agreed timetable.

\section{Conclusion}

The importance of this research is that the house building industry has the potential to address some of the key challenges facing the UK's construction industry

However, the traditional construction methods used by the housing industry have struggled to meet these challenges; initial research suggested that using OSM in place of the traditional approaches could contribute to achieving the government and industry targets; but, in order to achieve these improvements, this research has established the need for a robust decision making system at the very early stages of house building projects. To be able to achieve this goal, the paper revealed that the decision for using off-site construction methods needs to be better understood.

Making a decision is an important part of all construction industry sectors, where specialists apply their knowledge that fit a robust set of indicators; relying upon analysis of massive amounts of information, facts and belief. Decision making criteria used to evaluate OSM in house building if better understood, will become more recognized and accepted by end users, builders, regulators, lenders and government and clients. This research has identified the key drivers, constraints, and factors of using OSM for house building. It established the interrelationships between them by revealing that the application of OSM systems in housing can be part of a strategy to speed up onsite activities, quality of end facility, predictability of quality and performance and increase overall productivity, reduce labour onsite with its associated costs, provide fewer trades and interfaces to manage and coordinate onsite, and minimise environmental impacts.
This paper provides the basis to help understand what key drivers, constraints and factors that exist in the house building industry; all of which need to be considered at the very early stage in making a decision to use OSM in house building projects. This work has developed a conceptual model that describes the relationships between the identified key drivers, constraints and factors in house building decision making. The model clearly indicates the significance of feedback and continuous improvement of the quality of the decision making.

The research findings are based on data collected from the UK house building industry and therefore may not claim to provide the views and opinions of the entire construction industry. It is also important to note that the research focuses at the very early stage of the project, at the time when the contractor or builder is probably yet to be appointed.

Having identified the factors, drivers and constraints; the next step for the research is to focus on the global research aim which is the development of a model that now maps, measures and evaluates the relationship and impact of the factors, drivers and constraints in order to provide a Decision Evaluation Model (DEM) to determine when to manufacture off-site or on-site for the construction of house building projects in the UK.

\section{References}

Armstrong, J., Dixon, R., and Robinson, S. (1999). The Decision Makers: Ethics for Engineers. Thomas Telford Publishing, London.

Blismas, N.G. and Wakefield, R. (2007). Drivers, Constraints and the Future of OffSite Manufacture in Australia. Produced by CRC for Construction Innovation Special Edition 2008. QUT, 27575.

Blismas, N.G., Gibb, A.G.F., and Pasquire, C.L., (2006). Benefit evaluation for offsite production in construction. Construction Management and Economics, 24 (2), 121-130.

Burgan, B.A. and Sansom M.R. (2006). Sustainable steel Construction. Journal of Constructional Steel Research, 62(11), 1178-1183.

Choo, C. (2006). The Knowing Organization: How organizations use information to construct meaning, create knowledge, and make decisions, 2nd ed. Oxford University Press, Oxford.

CIRIA and Gibb, A. (2000). Client's Guide and Tool Kit for Standardisation and pre-assembly, Construction Industry Research and Information Association, Report CP/75, 70 pp. ISBN 0860175448.

Construction Excellence (2006). Movement for Innovation (M4I), London.

Crowley, A. (1998). Construction as Manufacturing Process: lessons from the automotive industry. Computers and Structures, 67,389-400.

Egan, J. (1998). Rethinking Construction: Accelerating Change. Department of the Environment, Transport and the Regions, London.

Housing Forum (2004). Manufacturing Excellence: UK capacity in off-site manufacturing. London: The Housing Forum.

Gann, D. (1996). Construction as a Manufacturing Process - Similarities and differences between industrialised housing and car production in Japan. Construction Management and Economics, (14), 437 450. 
Gibb, A. (2001). Standardisation and Pre-assembly: distinguishing myth from reality using case study research. Construction management and economics, 19, $307-315$.

Gibb, A. and Pendlebury M. (2005). Glossary of Terms. Buildoffsite: Prompting Construction offsite, London.

Gidado, K. (2013). Engineering, Project, and Production Management: Lessons Learnt from Each Other. Journal of Engineering, Project, and Production Management, 3(1), 1.

Goulding, J., Rahimian, F., Arif, M., and Sharp, M. (2012). Offsite Construction: Strategic Priorities for Shaping the Future Research Agenda. Architectoni.ca 2012, 1, 62-73.

Goodier, I. and pan, W. (2010). The Future of Offsite in Housing. 3rd international World of Construction Project Management Conference. Coventry University, Coventry, UK.

Jaillon, L. and Poon S. (2009). The Evolution of Prefabricated Residential Building Systems in Hong Kong: A review of the public and the private sector. Automation in Construction, 18, 239-248.

Lucey T. (1997). Management Information Systems, 8th ed. DP Publications, London.

Mullens, A. and Arif, M. (2006). Structural Insulated Panel: Impact on the Residential Construction Process. Journal of Construction Engineering and Management (ASCE), 132(7), 786-794.

Nahmens, I. and Mullens, M. (2009). The Impact of Product Choice on Lean Homebuilding. Construction Innovation: Information, Process, Management, 9(1), 84-100.

NHBC House (2009). Defining A Fabric Energy Efficiency Standard for Zero Carbon Homes: Executive Summary of Task Group Recommendations, November 2009, London.

Ogden, R. (2010). Year Book: the Buildoffsite vision. July, 2010, Buildoffsite, London.

Pan, W., Dainty, A.R., and Gibb, A.G. (2004). Encouraging the Appropriate Use of Off-Site Production (OSP): Perspectives of designers. The 2nd CIB SC international Symposium, Beijing, China.

Pan, W., Gibb, A., and Dainty, D. (2005). Off-site Methods of Construction in Housing: Perspectives and Practices of leading UK House-builders. Published by Buildoffsite.Loughborough University, Loughborough, UK.

Pan, W., Gibb, A. G. F., and Dainty, A. R. J. (2007). Perspectives of UK House-builders on the use of OffSite Modern Methods of Construction, Construction Management \& Economics, 25,183-194.

Pan, W. and Arif, M. (2011). Manufactured Construction: Revisiting the construction-manufacturing relations. Procs 27th Annual ARCOM Conference, Bristol, UK, 105-114.

Pan, W., Gibb, A. G. F., and Dainty, A. R. J. (2008). Leading UK house-builder's Utilisation of offsite modern methods of construction. Building Research and Information, 36(1), 56-67.

Polat, G., Arditi, D., Ballard, G., and Mungen, U. (2006). Econmics of on-site vs. off-site fabrication of rebar. Construction Management and Economics, 24, 11851198.

Pasquire, C. and Gibb, A. (2002). Considerations for Assessing the Benefits of Standardisation and Preassembly. Journal of Financial Management of Property and Construction, 7(3), 151-61.
Pasquire, C., Gibb, A. and Blismas, N. (2004). Off-Site Production: Evaluating the Drivers and Constraints. Proceedings of the 12th Annual Conference on Lean Construction, Copenhagen, Denmark, 3-4 August.

Ross, K., Cartwright, P., and Novakovic, O. (2006). A Guide to Modern Methods of Construction. The BRE Housing Innovation Centre Published by IHS BRE Press on behalf of NHBC Foundation.

Venables, et al. (2004). Modern methods of construction in Germany: playing the off-site rule. Report - Pera Innovation on behalf of the Department of Trade and Industry, UK

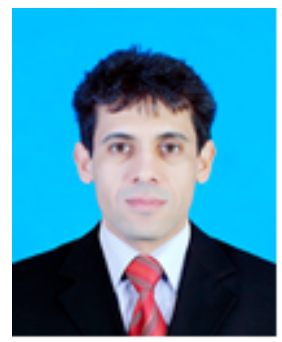

Hussein Elnaas is a $\mathrm{PhD}$ candidate in the School of Environment and Technology, the Faculty of Science and Engineering at the University of Brighton, Brighton, UK. He holds an EMng. in Civil Engineering, MSc. in Project Management for Construction, and Dip-Eng. in Construction Science. He has also 10 years experience in the construction industry practiced as a Site Engineer, Construction Manager and Project Manager. His research interests include decision making and analysis, decision support systems, innovation, and building information modelling.

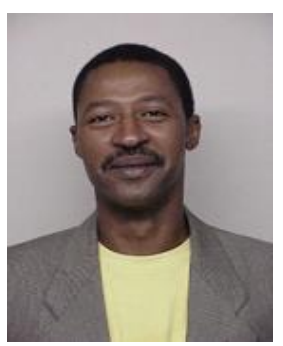

Kassim Gidado is a Principal Lecturer at the University of Brighton. He practiced in the construction industry as a site engineer, structural engineer, resident engineer, planning engineer and project manager in a number of countries. He is a Member of the Chartered Institute of Building, Member of the Association of Building Engineers, and Member of the Institute for Learning and Teaching in Higher Education. He joined the University of Brighton in 1992.

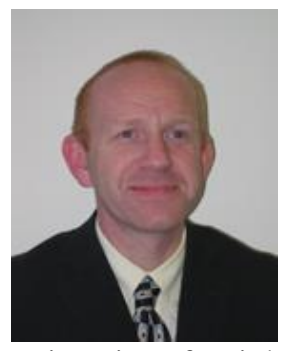

Philip Ashton is a Principal Lecturer at the University of Brighton. He is a Member of the Chartered Institute of Building, and Member of the Association for Project Management. Having worked extensively as a project manager throughout the UK construction industry; he joined the University of Brighton in 2003, and became the Head of the Built Environment \& Civil Engineering Division in 2005. 